\title{
The effect of vibrating positive expiratory pressure therapy on refractory Mycoplasma pneumoniae pneumonia prognosis in children
}

\author{
Jiali Sun, Jinglong Chen, Libo Wang, Aizhen Lu \\ Departments of Pneumonology, Children's Hospital of Fudan University, Shanghai, China \\ Contributions: (I) Conception and design: A Lu; (II) Administrative support: None; (III) Provision of study materials or patients: None; (IV) \\ Collection and assembly of data: J Sun, J Chen; (V) Data analysis and interpretation: J Sun, J Chen, A Lu; (VI) Manuscript writing: All authors; (VII) \\ Final approval of manuscript: All authors. \\ Correspondence to: Aizhen Lu, MD, PhD. Children's Hospital of Fudan University, 399 Wan Yuan Road, Shanghai 201102, China. \\ Email: zal2008@163.com.
}

\begin{abstract}
Background: It is well documented that vibration techniques and positive expiratory pressure (PEP) can improve airway clearance, however, few clinical trials have studied the efficacy of vibrating PEP therapy on refractory Mycoplasma pneumoniae (M. pneumoniae) pneumonia (RMPP) in children. This study aimed to explore using vibrating PEP therapy in children with RMPP.

Methods: Sixty participants in the remission stage of RMPP were recruited into this randomized study and divided into two groups. The Acapella group ( $n=30)$ used the Acapella ${ }^{\circledR}$ Choice twice daily for 2 months to clear their airways. The control group $(n=30)$ used traditional chest percussion or postural drainage to mediate sputum expectoration. The groups administered their respective treatments at home and were followed up weekly. Participants kept a record of their treatment and condition in a daily log. The primary outcome of this study was the resolution of chest images, and the secondary outcome was the sputum period. Results: There was no significant difference in sex or age distribution between the two groups. There were no significant differences at baseline between the groups in the location of their lesions $(\mathrm{P}=0.11)$. After 2 months of treatment, there was a better resolution of chest images in the Acapella group $(\mathrm{P}=0.00)$ compared with the control group. Additionally, the mean sputum period was significantly shorter for the Acapella group than for the control group (Acapella: $7.97 \pm 1.54$ days; control: $11.90 \pm 1.64$ days; $\mathrm{P}=0.00$ ).

Conclusions: Vibrating PEP therapy is an effective therapy for children with RMPP, both in airway clearance and the resolution of lung abnormalities.
\end{abstract}

Keywords: Vibrating; positive expiratory pressure (PEP); refractory M. pneumoniae pneumonia (RMPP); Acapella ${ }^{\circledR}$ Choice; lung rehabilitation

Submitted Aug 11, 2020. Accepted for publication Dec 10, 2020.

doi: $10.21037 /$ tp-20-237

View this article at: http://dx.doi.org/10.21037/tp-20-237

\section{Introduction}

Mycoplasma pneumoniae (M. pneumoniae) is a dominant causative pathogen of community-acquired respiratory tract infections in children (1). Although pneumonia caused by $M$. pneumoniaeis usually benign and selflimiting, increasing numbers of cases are known to further develop into refractory $M$. pneumoniae pneumonia (RMPP) (2-4). Although effective integrated strategies have been developed to treat this condition $(4,5)$, the prognosis of RMPP is unsatisfactory; this disease can lead to disability and sequelae (6-10), including atelectasis, bronchiectasis, occlusive bronchitis, and bronchiolitis obliterans.

Pulmonary hypersecretion and mucosal damage to 

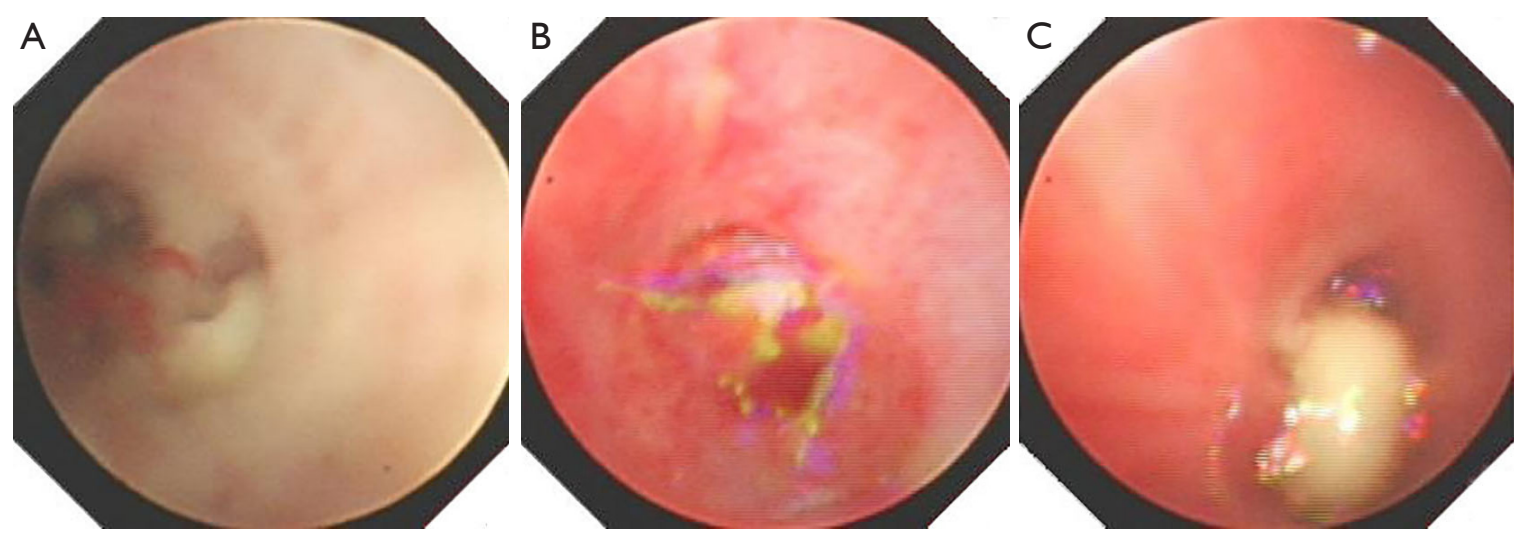

Figure 1 Mucus lesions. (A) Mucosal necrosis; (B) poor bronchial ventilation; (C) phlegm embolism.

the airways have been observed in RMPP patients; these are associated with the poor prognosis of RMPP $(11,12)$. Eliminating these secretions and reopening the airways is essential in RMPP rehabilitation. Acapella ${ }^{\circledR}$ Choice (Smiths Medical) combines high-frequency vibration therapy and positive expiratory pressure (PEP) therapy. Vibration therapy loosens viscous pulmonary secretions by vibrating the flow of air through the lungs. PEP therapy, which expands the airway using positive pressure generated by exhalation, then pushes loosened secretions into the large upper trachea, where they are easily discharged by coughing. Acapella ${ }^{\circledR}$ Choice facilitates bronchial clearance of secretions, which increases the quantity of expectorated mucus and improves pulmonary function $(13-15)$. At present, Acapella ${ }^{\circledR}$ Choice is widely used in the treatment of chronic respiratory diseases, including chronic bronchitis, cystic fibrosis, and bronchiectasis (16-19). We hypothesize Acapella ${ }^{\circledR}$ Choice will facilitate the drainage of pulmonary secretions in the small airways and assist in the repair of mucosal damage caused by $M$. pneumonia infection in RMPP patients.

We present the following article in accordance with the STROBE reporting checklist (available at http://dx.doi. org/10.21037/tp-20-237).

\section{Methods}

\section{Participants}

Sixty children with stable RMPP that attended the Children's Hospital of Fudan University between January 2018 and December 2019 were enrolled in this study. Serologic tests confirmed M. pneumoniae infection (detection of M. pneumoniae IgM by ELISA) and/or PCR [detection of $M$. pneumoniae in bronchoalveolar lavage fluid (BALF)]. RMPP is clinically defined as a case of $M$. pneumoniae pneumonia with prolonged fever accompanied by the deterioration of radiological findings despite appropriate treatment with macrolides for 7 days or more $(1,20)$. Other study inclusion criteria included the following: (I) mucosal damage, including rough membranes, swelling, increased secretions, mucosal erosion, and poor bronchial ventilation or occlusion, was observed in the acute stage of disease by bronchoscopy (Figure 1); (II) patients were in a stage of clinical remission, meaning they had received treatment for at least 1 month and there were no current clinical manifestations of the condition, including fever or frequent cough, and their results on laboratory tests, including C-reactive protein (CRP) and erythrocyte sedimentation rate (ESR), were in the normal range; (III) chest radiographs or lung computed tomography (CT) still showed pulmonary abnormalities, including massive exudation, consolidation, atelectasis, bronchiectasis, and occlusive bronchitis. Children with immune deficiencies, chronic diseases, or heart diseases were excluded. All participants produced negative results on purified protein derivative tests, as well as BALF tests for respiratory syncytial viruses, influenza viruses, adenoviruses, parainfluenza viruses, and chlamydia trachomatis. The participants also produced negative results in BALF bacterial cultures and double-negative blood cultures. The study was conducted in accordance with the Declaration of Helsinki (as revised in 2013). The study was approved by the Ethics Committee of Children's Hospital of Fudan University [No. (2016)87] and informed consent was obtained from all patients' guardians. 
Day $(1,2,3 \ldots \ldots 60)$

\section{Daily Log}

Date

\section{Questionnaire}

1. Do you cough today? $\square$ Yes; $\square$ NO;

2. Do you produce sputum today? $\square$ Yes; $\square$ NO;

3. Do you feel chest tightness today? $\square$ Yes; $\square \mathrm{NO}$;

4. Do you have difficulty breathing? $\square$ Yes; $\square$ NO;

5. Does the performance affect your usual activity today? $\square$ Yes; $\square$ NO;

6. Does the performance affect your sleep today? $\square$ Yes; $\square$ NO;

7. Frequency of treatment today: $\square$ Once; $\square$ Twice; $\square$ Three times;

8. Time of performance every time: $\min$

9. Side effects of the treatment:

Figure 2 Daily Log.

\section{Study design}

Sixty Participants were divided into the Acapella group and the control group by computer-generated randomization. As no suitable data was available to calculate a sample size, we estimated sample size as 30 in each group (21). Participants in the Acapella group $(\mathrm{n}=30)$ were required to administer Acapella ${ }^{\circledR}$ Choice twice daily for 2 months, while control group participants $(n=30)$ were required to receive chest percussion therapy twice daily for 2 months. These treatments were carried out after patients were discharged, meaning that they perform the therapy at home. Throughout this period, participants kept a daily log where they provided answers to the following: whether they had a cough, had produced sputum, or had chest tightness or difficulty breathing; whether their usual activity or sleep was affected; frequency of treatment, whether use of Acapella or chest percussion; and side effects of their treatment (Figure 2). Participants were followed up weekly by phone or home visits, depending on their needs, and encouraged to practice airway clearance and fill in their daily log regularly.

\section{Acapella performance}

To use Acapella ${ }^{\circledR}$ Choice, a physiotherapist first adjusts the resistance according to the device instructions. A suitable resistance is one on which a patient can comfortably exhale three to four times longer. The patient then puts the mouthpiece in their mouth, takes a deep breath, holds for two to three seconds, and then exhales for three to four seconds. A patient should perform 10 breaths, followed by two to three huff coughs to expectorate. Each treatment should last 10-20 minutes. In this study, participants were taught to use Acapella ${ }^{\circledR}$ Choice correctly before administering this treatment at home. They were required to observe whether the rocker in the Acapella device was vibrating when they exhaled to ensure that PEP was generated.

\section{Outcomes}

The primary outcome of this study was the resolution of chest image abnormalities after 2 months treatment. Chest images were evaluated by two radiologists who were blind to treatment allocation. They graded the images as showing full resolution, partial resolution, meaning the lesions were smaller than in previous findings, or no resolution. The secondary outcome was the participants' sputum period, being the number of days that participants expectorated sputum. The participants' demographic data were also collected.

\section{Statistical analysis}

Statistical analyses were performed with SPSS Version 18.0 (SPSS Inc.). P values of less than 0.05 were considered 


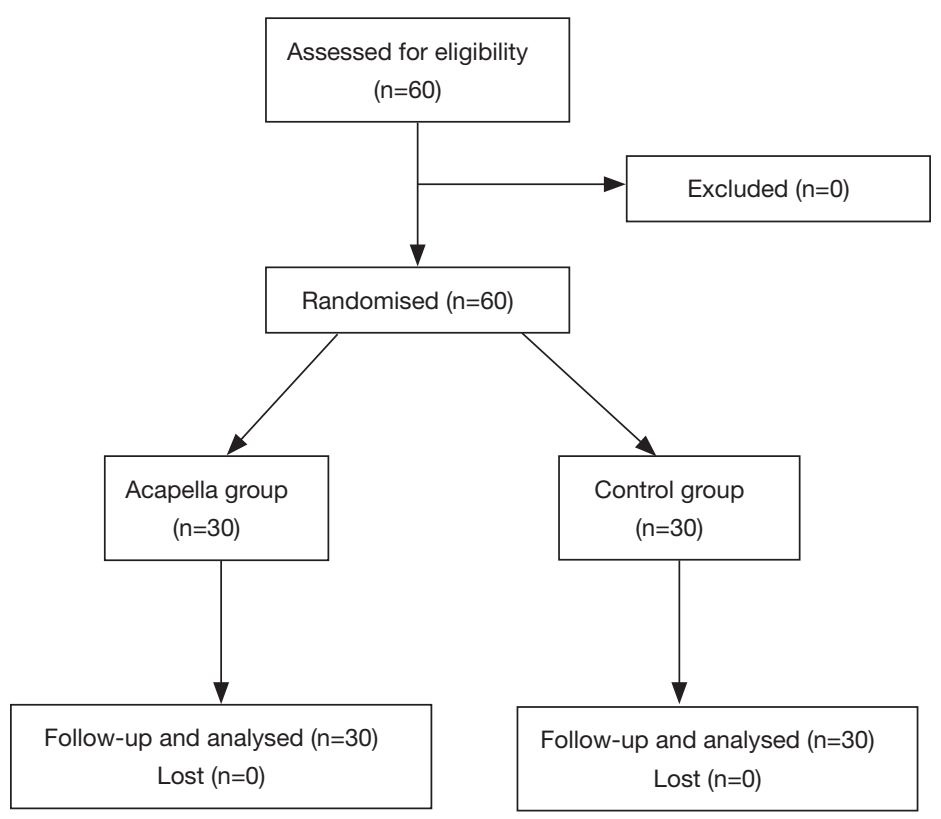

Figure 3 Flow diagram of the progress of patients.

Table 1 Primary lesion location at baseline

\begin{tabular}{lccc}
\hline Primary lesion location & Acapella group, $n=30$ & Control group, $n=30$ & P value \\
\hline Left upper lobe $(n)$ & 4 & 1 \\
Lingula $(n)$ & 1 & 2 \\
Left lower lobe $(n)$ & 12 & 12 \\
Right upper lobe $(n)$ & 7 & 2 \\
Right middle lobe $(n)$ & 1 & 9 \\
Right lower lobe $(n)$ & 5 & \\
\hline
\end{tabular}

statistically significant. Count data were analyzed with the chi-square test, normally distributed measurement data were analyzed with the $t$-test, and non-normally distributed measurement data and ordinal data were analyzed with nonparametric tests.

\section{Results}

\section{Demographic data}

All 60 participants completed this study, and there was no lost to follow-up (Figure 3). The Acapella group comprised 12 males and 18 females, and the control group comprised 17 males and 13 females. There were no significant differences in sex distribution between the two groups $(\mathrm{P}=0.19)$. The average age of the Acapella group was $83.9 \pm 23.6$ months (range: 54-134 months; median: 78.5 months), and the average age of the control group was $77.3 \pm 26.0$ months (range: $49-131$ months; median: 68.5 months). There were no significant differences in age distribution between the two groups $(\mathrm{P}=0.31)$. All participants completed the daily log, and all reported that they adhered the corresponding treatment.

\section{Imaging findings}

At baseline, imaging demonstrated abnormalities, including consolidation and atelectasis in the lungs of all participants. There were no differences in lesion location between the two groups (Table 1) $(\mathrm{P}=0.11)$. However, the Acapella group 

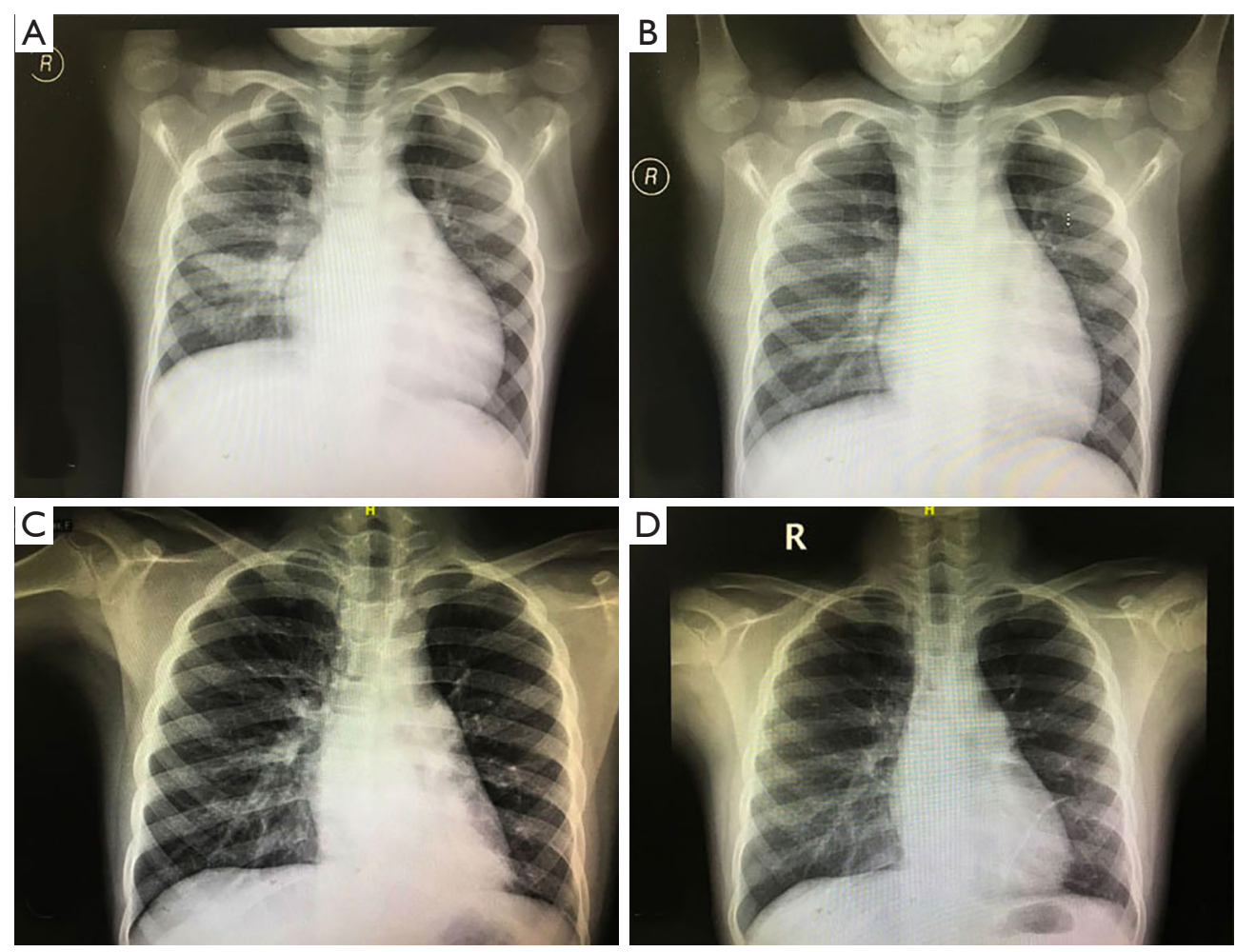

Figure 4 Examples of imaging findings. Case 1: (A) consolidation in right middle lobe; (B) consolidation completely resolved after using the Acapella device for 2 months. Case 2: (C) consolidation in left lower lobes; (D) consolidation resolved after using the Acapella device for 2 months.

Table 2 Lesion resolution after treatment

\begin{tabular}{lccc}
\hline Lesion resolution & Acapella group, $n=30$ & Control group, $n=30$ & P value \\
\hline Almost no resolution [n (\%)] & $2(6.7)$ & $4(13.3)$ & 0.00 \\
Partial resolution [n (\%)] & $9(30.0)$ & $23(76.7)$ & $3(10.0)$ \\
Full resolution [n (\%)] & $19(63.3)$ & & \\
\hline
\end{tabular}

showed better resolution of abnormalities than the control group after 2 months of treatment (Figure 4 and Table 2) $(\mathrm{P}=0.00)$. The proportion of participants that demonstrated complete resolution in the Acapella group (63.3\%) was higher than the control group (10.0\%) (Table 1) $(\mathrm{P}=0.00)$.

\section{Sputum period}

The baseline findings were that all participants had sputum in their lungs. Throughout their respective therapies, this sputum was gradually expectorated. The Acapella group's mean sputum period was significantly shorter than the control group (Acapella group: $7.97 \pm 1.54$ days; control group: $11.90 \pm 1.64$ days; $\mathrm{P}=0.00$ ).

No participants in either group reported any side effects.

\section{Discussion}

This study showed that Acapella ${ }^{\circledR}$ Choice is an acceptable method to repair airway damage in RMPP patients. To our knowledge, this has not been previously reported. Hypersecretion of pulmonary secretions, as well as mucosal damage, have been observed in RMPP patients and are associated with an increased incidence of sequelae $(11,12)$. Airway clearance is essential for the repair of mucosal damage. The Acapella device combines vibration techniques 
and PEP to facilitate the loosening, mobilization, and expectoration of secretions. In adults, the active cycle of breathing technique (ACBT) is often used to help patients expectorate and restore lung function (21-23). However, ACBT is not frequently used in children, as the techniques involved, including breathing control, thoracic expansion exercises, and forced expiration, are complicated for them to perform. Acapella ${ }^{\circledR}$ Choice, however, is more accessible for children to use than other therapies and is, therefore, better received by parents, resulting in better compliance. In this study, we found that children with RMPP preferred the Acapella device over chest percussion therapy as a method to clear their airways and promote pulmonary rehabilitation.

In this study, we found a better resolution of lung abnormalities in participants treated with Acapella ${ }^{\circledR}$ Choice. The Acapella group also had shorter sputum periods. These results may be related to a reduction of obstructive sputum in the small airway, reduction of bronchial inflammation, and repair of damage to the airways treated by Acapella ${ }^{\circledR}$ Choice. PEP devices have been reported to be effective in treating diseases, including bronchiectasis and chronic obstructive pulmonary disease (COPD), as well as the treatment of patients in recovery from thoracic surgery by promoting airway clearance and the restoration of lung function (21-25). In these studies, forced expiratory volume in one second was the most frequently measured primary outcome, and sputum volume or weight was the secondary outcome. In this study, resolution of lung images was used as primary outcome as it is a relatively objective measurement. In addition, spirometry measurements are difficult to young children. We use sputum period as the secondary outcome because it isn't easy for children to spit out the sputum, which they often swallow. A systematic review showed that PEP device appeared to be effective for children with stable bronchiectasis, however, the effectiveness in people with an acute exacerbation of bronchiectasis is unknown (17). Another review showed that PEP was also effective in exacerbations of cystic fibrosis (26). Our findings were consistent with these reports, suggesting that PEP was effective for children with stable RMPP.

Our study had some limitations. The first was that a participant's sputum period was from their self-report, which cannot be objectively evaluated. However, participants were contacted weekly to encourage adherence to their treatment plan, as well as regular record-keeping. The second limitation was that we had an estimated sample size, which may reduce the validity of our study. Additionally, participants were observed for only 2 months; a longer period of observation would produce more powerful results. The third limitation was that our participants were children. While easier than other therapies, the Acapella device is still not easy for children to use. Children also tend to swallow some secretions, as they have difficulty expectorating them, which may have impacted the participants' records of expectorated secretions.

In summary, Acapella ${ }^{\circledR}$ Choice is an effective method of airway clearance and resolution of lung abnormalities in children with RMPP, and using this device may improve the prognosis of patients with this condition.

\section{Acknowledgments}

Language polishing: Language was polished by expert B. Madden and J. Chapnick from AME Editing Service (http:// editing.amegroups.cn/\#editing).

Funding: Supported by the National Natural Science Funds (81601332), China.

\section{Footnote}

Reporting Checklist: The authors have completed the STROBE reporting checklist. Available at http://dx.doi. org/10.21037/tp-20-237

Data Sharing Statement: Available at http://dx.doi. org/10.21037/tp-20-237

Peer Review File: Available at http://dx.doi.org/10.21037/tp20-237

Conflicts of Interest: All authors have completed the ICMJE uniform disclosure form (available at http://dx.doi. org/10.21037/tp-20-237). The authors have no conflicts of interest to declare.

Ethical Statement: The authors are accountable for all aspects of the work in ensuring that questions related to the accuracy or integrity of any part of the work are appropriately investigated and resolved. The study was conducted in accordance with the Declaration of Helsinki (as revised in 2013). The study was approved by the Ethics Committee of Children's Hospital of Fudan University [No. (2016)87] and informed consent was obtained from all 
patients' guardians.

Open Access Statement: This is an Open Access article distributed in accordance with the Creative Commons Attribution-NonCommercial-NoDerivs 4.0 International License (CC BY-NC-ND 4.0), which permits the noncommercial replication and distribution of the article with the strict proviso that no changes or edits are made and the original work is properly cited (including links to both the formal publication through the relevant DOI and the license). See: https://creativecommons.org/licenses/by-nc-nd/4.0/.

\section{References}

1. Lee KY. Pediatric respiratory infections by Mycoplasma pneumoniae. Expert Rev Anti Infect Ther 2008;6:509-521.

2. Lee KY, Lee HS, Hong JH, et al. Role of prednisolone treatment in severe Mycoplasma pneumoniae pneumonia in children. Pediatr Pulmonol 2006;41:263-8.

3. Miyashita N, Obase Y, Ouchi K, et al. Clinical features of severe Mycoplasma pneumoniae pneumonia in adults admitted to an intensive care unit. J Med Microbiol 2007;56:1625-9.

4. Lu A, Wang L, Zhang X, et al. Combined treatment for child refractory Mycoplasma pneumoniae pneumonia with ciprofloxacin and glucocorticoid. Pediatr Pulmonol 2011;46:1093-7.

5. Tamura A, Matsubara K, Tanaka T, et al. Methylprednisolone pulse therapy for refractory Mycoplasma pneumoniae pneumonia in children. J Infect 2008;57:223-8.

6. Leong MA, Nachajon R, Ruchelli E, et al. Bronchitis obliterans due to Mycoplasma pneumonia. Pediatr Pulmonol 1997;23:375-81.

7. Kim CK, Kim SW, Kim JS, et al. Bronchiolitis obliterans in the 1990s in Korea and the United States. Chest 2001;120:1101-6.

8. Wachowski O, Demirakça S, Müller KM, et al. Mycoplasma pneumonia associated organising pneumonia in a 10 year old boy. Arch Dis Child 2003;88:270-2.

9. Hanzawa F, Fuchigami T, Ishii W, et al. A 3-year-old boy with Guillain-Barre syndrome and encephalitis associated with Mycoplasma pneumoniae infection. J Infect Chemother 2014;20:134-8.

10. You SY, Jwa HJ, Yang EA, et al. Effects of Methylprednisolone Pulse Therapy on Refractory Mycoplasma pneumoniae Pneumonia in Children. Allergy Asthma Immunol Res 2014;6:22-6.
11. Wang L, Lu S, Feng Z, et al. The early examination of combined serum and imaging data under flexible fiberoptic bronchoscopy as a novel predictor for refractory Mycoplasma pneumoniae pneumonia diagnosis. Medicine (Baltimore) 2017;96:e9364.

12. Zhang Y, Chen Y, Chen Z, et al. Effects of bronchoalveolar lavage on refractory Mycoplasma pneumoniae pneumonia. Respir Care 2014;59:1433-9.

13. van der Schans CP. Airway clearance: assessment of techniques. Paediatr Respir Rev 2002;3:110-4.

14. Hess DR. Secretion clearance techniques: absence of proof or proof of absence? Respir Care 2002;47:757-8.

15. McCool FD, Rosen MJ. Nonpharmacologic airway clearance therapies: ACCP evidence-based clinical practice guidelines. Chest 2006;129:250S-259S.

16. Wilson LM, Morrison L, Robinson KA. Airway clearance techniques for cystic fibrosis: an overview of Cochrane systematic reviews. Cochrane Database Syst Rev 2019;(1):CD011231.

17. Lee AL, Burge AT, Holland AE. Airway clearance techniques for bronchiectasis. Cochrane Database Syst Rev 2015;(11):CD008351.

18. Lee AL, Burge AT, Holland AE. Positive expiratory pressure therapy versus other airway clearance techniques for bronchiectasis. Cochrane Database Syst Rev 2017;(9):CD011699.

19. Osadnik CR, McDonald CF, Jones AP, et al. Airway clearance techniques for chronic obstructive pulmonary disease. Cochrane Database Syst Rev 2012;(3):CD008328.

20. The Subspecialty Group of Respiratory, Pediatric Society, Chinese Medical Association. Guidelines for management of community acquired pneumonia in children (the revised edition of 2013) (I). Zhonghua Er Ke Za Zhi 2013;51:745-52.

21. Patterson JE, Bradley JM, Hewitt O, et al. Airway clearance in bronchiectasis: a randomized crossover trial of active cycle of breathing techniques versus Acapella. Respiration 2005;72:239- 42.

22. Patterson JE, Hewitt O, Kent L, et al. Acapella versus 'usual airway clearance' during acute exacerbation in bronchiectasis: a randomized crossover trial. Chron Respir Dis 2007;4:67-74.

23. Üzmezoğlu B, Altıay G, Özdemir L, et al. The Efficacy of Flutter ${ }^{\circledR}$ and Active Cycle of Breathing Techniques in Patients with Bronchiectasis: A Prospective, Randomized, Comparative Study. Turk Thorac J 2018;19:103-9.

24. Cho YJ, Ryu H, Lee J, et al. A randomised controlled trial comparing incentive spirometry with the Acapella ${ }^{\circledR}$ 
device for physiotherapy after thoracoscopic lung resection surgery. Anaesthesia 2014;69:891-8.

25. Fridlender ZG, Arish N, Laxer U, et al. Randomized controlled crossover trial of a new oscillatory device as add-on therapy for COPD. COPD 2012;9:603-10.

Cite this article as: Sun J, Chen J, Wang L, Lu A. The effect of vibrating positive expiratory pressure therapy on refractory Mycoplasma pneumoniae pneumonia prognosis in children. Transl Pediatr 2021;10(2):315-322. doi: 10.21037/tp-20-237
26. Morrison L, Innes S. Oscillating devices for airway clearance in people with cystic fibrosis. Cochrane Database Syst Rev 2017;5:CD006842.

(English Language Editors: B. Madden and J. Chapnick) 